\title{
Accuracy Characteristics of the Electronics of Waverider Buoys Used in the ARSLOE
}

\author{
RICHARD L. RIBE
}

(Invited Paper)

\begin{abstract}
During the Atlantic Remote Sensing Land Ocean Experiment (ARSLOE), October-November, 1980, a large number of meteorological and oceanographic instruments, especially wavemeasurement instruments, were deployed in the ocean near the Army Corps of Engineers Pier, Duck, NC. About nine Waverider ${ }^{1}$ buoys were deployed in an approximately rectangular pattern, about $30 \mathrm{~km}$ wide by $40 \mathrm{~km}$ seaward. The Waveriders were an accepted reference for study of other wave-measurement instrument systems. Almost all of the Waverider buoys were calibrated on the rotating-arm facility of the NOAA, Engineering Support Office. Pre- and post-deployment calibrations formed the basis for tables and equations for correction of the Waverider measurements. The calibrations discussed here established that the Waveriders were measuring lower than specification, averaging about 5 percent low (10 percent for variance spectra coefficients.) Corrections for effects of fluctuations in water temperature on Waverider sensitivity were required and are provided. The manufacturer's modification to prevent future drift in sensitivity is also described.
\end{abstract}

\section{INTRODUCTION}

W TAVERIDER buoys have been in use since about 1966 and are the principal instrument for national wave measurement programs for many countries. It has frequently been assumed that the Waverider sensitivity remains within 3 percent of specified one volt per meter of wave elevation throughout the useful life of the Waverider. During the earlier years of Waverider use, no calibration apparatus was available which could accept a complete Waverider buoy, although approximate calibrations over a limited range of period of vertical motion could be obtained by suspending the buoy from an elastic cord or spring and maintaining vertical oscillations manually.

In support of their respective waves climate programs, the United States, Canada, and England developed apparatus to calibrate Waveriders on a rotating-arm, vertical circle of motion. France is planning apparatus for generating pure vertical motion. Venezuela has had a device with pure vertical motion, based on the Scotch-yoke principle. Such devices can improve ocean wave measurement accuracy by determining error, possibly on the order of five percent, in Waverider sensitivity versus period of motion. Resultant correction factors are a function of period or frequency and, therefore, must be

Manuscript received February 15, 1983 ; revised July 25, 1983. This paper is an expanded presentation of a paper presented at OCEANS'82, Marine Technology Society, IEEE Council on Oceanic Engineering, Washington, DC, Sept. 20-22, 1982.

The author is with the National Oceanic and Atmospheric Administration, Rockville, MD 20852.

1 Waverider and WAREP are Datawell proprietary names for the buoy and receiver system, respectively. applied to sinusoidal, Fourier components of a waves elevation time series or, as square of the transfer function, to the coefficients of the variance spectra.

The Waverider has a unique accelerometer design consisting of a cantilever-beam sensor mounted in the electrical field of an electrolytic fluid. The fluid conductivity has been carefully adjusted to provide the desired Waverider sensitivity and the associated electronic circuitry is designed to match the characteristics of each individual accelerometer. Under the design conditions, effect of fluctuations of temperature of this electrolyte fluid can be considered negligible. However, an increase in the electrical conductivity of the electrolyte of some Waveriders has caused a corresponding decrease in sensitivity and has made the assumption of insensitivity to temperature fluctuations no longer valid. This has increased the importance of applying corrections to Waverider measurements. Correction tables are available for the Waverider buoys used in the ARSLOE.

\section{WAVERIDERS ACCURACY CHARACTERISTICS}

All of the Waveriders used in the ARSLOE telemetered to individual Datawell WAREP receivers. Receiver errors were small compared to the buoy errors, but all of the receivers have an accuracy characteristic response at higher frequencies, Fig. 1, which is included in the calibrations of the buoys [1]. The receivers were calibrated with a WAREP Test Unit manufactured by Datawell. The Test Unit accuracy was established with a counter-timer. Thus traceability was established.

The Waveriders, exclusive of receiver accuracy, have a characteristic as illustrated in Fig. 2, [2, p. 57]. At the higher frequencies the deviations are caused by a combination of buoy hydrodynamic resonance and tether effects and are not included in calibrations.

The remaining, lower frequency deviation $(\Delta)$ of Fig. 2 is systematic, represented by (1), [2, p. 50] .

$$
\Delta=\frac{1}{\left[1+\left(\frac{T}{30.8}\right)^{4}\right]^{1 / 2}}-1 .
$$

Deviations $(\delta)$ from the relationship of (1) were obtained by calibration of the individual Waveriders. A polynomial of second order in period was fitted to the values of $\delta$ calculated for each calibration and used to provide correction ta- 


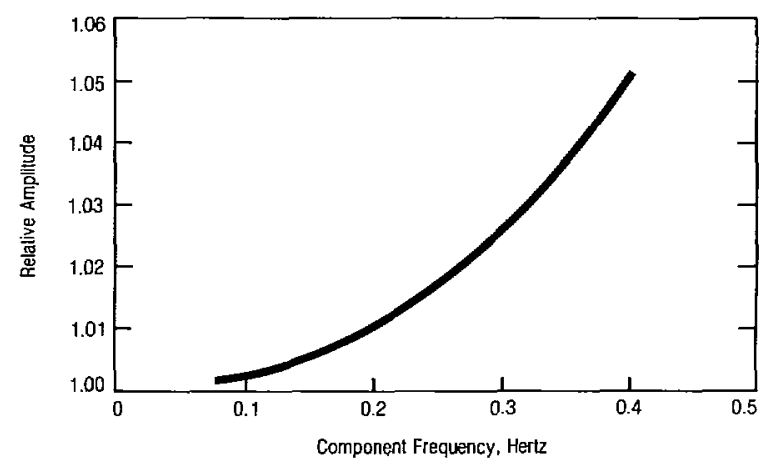

Fig. 1. WAREP high-frequency characteristic.

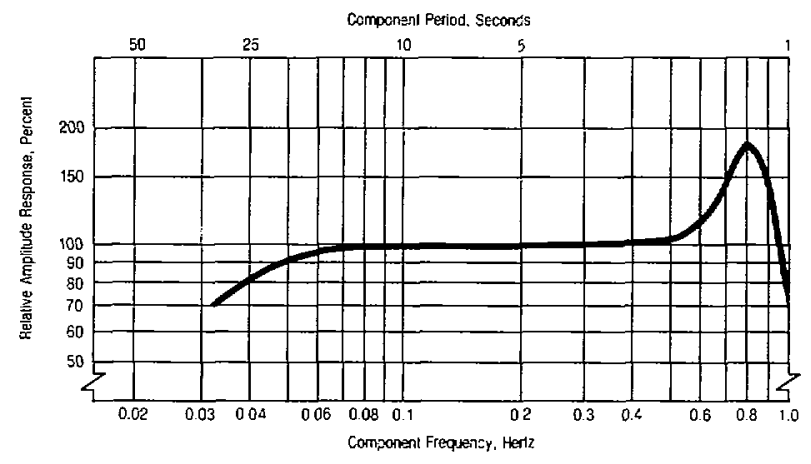

Fig. 2. Buoy frequency response.

bles [3] versus period and frequency. Corrections for variance spectra coefficients are also provided.

The Waverider buoy also causes large but systematic phase shifts on the individual Fourier components of wave records $[2$, p. 57]. The WAREP receiver can contribute additional phase shifts, the amount being dependent on presence or absence of low-pass filtering in the receiver. Corrections for these phase shifts are necessary if the wave records are used to study waveshapes.

\section{BUOY-ACCURACY STABILITY AND TEMPERATURE EFFECTS}

All of the Waverider buoys used in ARSLOE and calibrated at the Engineering Support Office exhibited sensitivity below 100 percent, averaging approximately 95 percent of the rated one volt per meter of wave elevation.

These sensitivities are determined after correction for the Datawell-specified decrease of sensitivity with increasing wave period, which is of significance for periods longer than about $8 \mathrm{~s}$. An example plot of these relationships is shown in Fig. 3.

Datawell now provides an improved modulator circuit in new Waveriders to eliminate the downward drift in sensitivity. This circuit can be installed in Waveriders of earlier manufacture and will bring the sensitivity back to within specification and eliminate further downward drift. Eventually, in possibly 10 to 15 years, the increase in electrical conductivity of the accelerometer electrolyte will exceed the ability of the new modulator circuit to compensate but, at that time, if the buoy is still serviceable, the accelerometer fluid can be replaced by Datawell.

In addition, corrections for the effect of changes in buoy

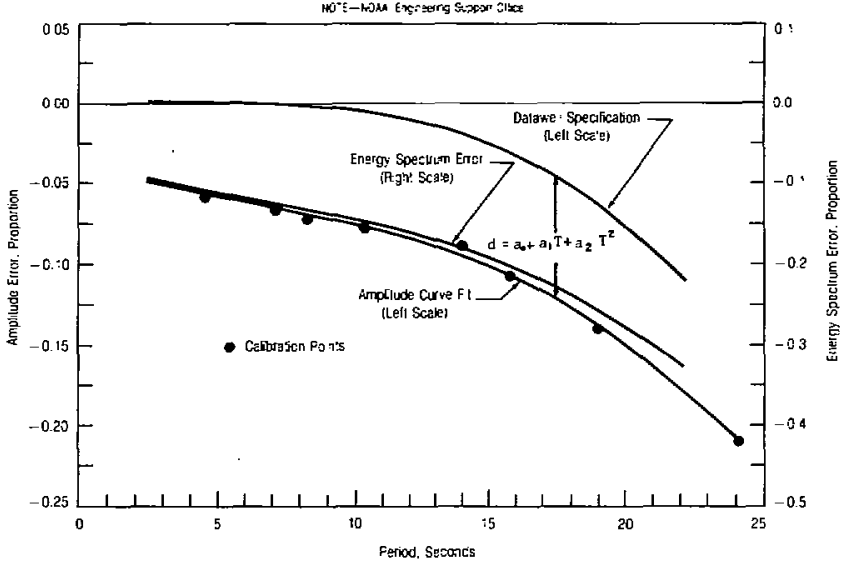

Fig. 3. Waverider 66967 predeployment calibration, 8/1/80.

TABLE I

REPRESENTATIVE SECTION OF THE TEMPERATURE COMPENSATION SENSITTVITY

\begin{tabular}{|c|c|c|c|c|}
\hline \multirow[t]{2}{*}{$\begin{array}{r}\text { Sensitivity at } \\
22.4^{\circ} \mathrm{C} \\
\end{array}$} & \multicolumn{4}{|c|}{ Increment to Add to the Calibration Sensitivity } \\
\hline & $22.4 \circ 0$. & 160 & $12^{11}$ & $8^{0}$ \\
\hline 1.00 & 0 & .001 & 0 & -.002 \\
\hline$M$ & 0 & .011 & .013 & 020 \\
\hline .96 & 0 & .016 & .023 & .029 \\
\hline .94 & 0 & .015 & .025 & $.03 n$ \\
\hline .92 & 0 & .017 & .029 & 039 \\
\hline .90 & 0 & .024 & .037 & 049 \\
\hline
\end{tabular}

(accelerometer fluid) temperature on buoy sensitivity must be applied. ${ }^{2}$ The accelerometers were designed to have minimum effect from temperature fluctuations, but increases in the fluid electrical conductivity have shifted the temperature effects from the design condition. Datawell has provided general temperature-compensation curves [3, Appendix, fig. 1] which were adapted to provide a sensitivity-correction table (Table I) which can be applied by using the ARSLOE preand post-deployment calibrations to determine the uncorrected sensitivity at $22.4^{\circ} \mathrm{C}$.

The table is based on the assumption that the temperature of the fluid in the accelerometer is the same as the water temperature at the ARSLOE site. Tests at the NOAA, Engineering Support Office, indicate this is a good assumption. The water temperature at ARSLOE varied approximately linearly from $22.4^{\circ} \mathrm{C}$ on October 1,1980 , to $10.2^{\circ} \mathrm{C}$ on November $30,1980$.

\section{CORRECTION TABLES}

Tables have been provided in [3] which allow correction of the Waverider wave measurements made during ARSLOE, both for the true, calibrated sensitivity at room temperature of $22.4^{\circ} \mathrm{C}$ and for the condition of water temperature less than the calibration temperature. In practice, the pre- and post-deployment calibrations were close enough to being equal that the calibration closest to wave measurement date

2 In some reports using or presenting ARSLOE Waverider measurements, most or all necessary corrections to the measu rements have been applied. The amount of correction should be determined before the measurements are used. 
can be used to correct the wave measurements. Then two approaches are possible.

The first approach would be to apply the tables to correct the component waves amplitude coefficient or variance spectra coefficient at the corresponding period or frequency. The second approach would be to apply both the Datawell relationship $(1)$ and the second-order equation for the deviation $(\delta)$ from this relationship to the amplitude or variance spectra coefficients in the appropriate manner as described in [3].

Either of these correction techniques will provide a buoy sensitivity for the Waverider electronics at $22.4^{\circ} \mathrm{C}$ estimated to be within one percent of the correct sensitivity. The buoy sensitivities are then corrected for the difference between the water temperature and $22.4^{\circ} \mathrm{C}$ using an expanded version of Table I.

\section{REFERENCES}

[1] J. G. A. van Breugel, "Preliminary manual of Waverider receiver type Mark II," Datawell bv., Haarlem, The Netherlands, undated.

[2] C. M. Verhagen, P. L. Gerritzen, and J. G. A. van Breugel,
"Operation and service manual for Waverider $(3000,4000,5000$, and 6000 series)" Datawell bv., Haarlem, The Netherlands, 1975.

[3] R. L. Ribe, "Calibrations, and energy spectrum correction factors for Waverider buoys deployed under the ARSLOE program," ARSLOE Informal Rep. 4, NOAA, Rockville, MD., Nov. 1981.

[4] R. L. Ribe, "Calibration accuracy and data correction for Waverider buoys deployed during ARSLOE," presented at OCEANS 82, Marine Technology Society, IEEE Council on Oceanic Engineering, Washington, DC, Sept. 20-22, 1982.

Richard L. Ribe received the M.S. degree in physics and the M.S. degree in aeronautical engineering from the University of Washington in 1964 and 1957, respectively. He received the B.S. degree in aeronautical engineering from the University of Minnesota in $195 \mathrm{l}$.

He currently works as a Physicist with the National Oceanic and Atmospheric Administration on ocean wave and other instrument systems.

\title{
Directional Wave Spectra Measured with a Cloverleaf Buoy During ARSLOE
}

\author{
HISASHI MITSUYASU AND TADAO KUSABA
}

(Invited Paper)

\begin{abstract}
The cloverleaf buoy is designed to determine the directional wave spectra with high directional resolution by measuring the vertical acceleration, surface slope, and curvature of the ocean wave surface. This paper describes the properties of the directional wave spectra measured with the cloverleaf buoy during the Atlantic Remote Sensing Land Ocean Experiment (ARSLOE). It is shown that the directional wave spectra measured under relatively constant wind agree fairly well with the similarity spectrum reported previously, but some differences are found in the spectral parameters. The differences in the scale parameters are attributed to unstable atmospheric conditions, though reasonable explanations for those in the shape parameters are difficult now.
\end{abstract}

\section{INTRODUCTION}

$\mathbf{T}$ HE DIRECTIONAL wave spectra in the ARSLOE area were measured with a cloverleaf buoy developed at Kyushu University. The cloverleaf buoy was deployed from the attending research vessel $(R / V)$ Cape Henlopen of the University of Delaware. During October 18-30, 1980, 53 sets of wave data

Manuscript received February 1, 1983; revised May 5, 1983. This work was supported by NOAA and the U.S. Army Corps of Engineers.

The authors are with the Research Institute for Applied Mechanics, Kyushu University 87, Hakozaki, Higashi-ku, Fukuoka 812, Japan. were obtained under various meteorological conditions including the passage of an extratropical low directly through the experimental area.

Since the directional resolving power of the cloverleaf buoy is high, one of the main objectives of the measurement was to obtain accurate directional wave data for the intercomparison of the data obtained with various directional buoys deployed in the ARSLOE area. Another objective was to investigate the properties of the directional wave spectrum.

The intercomparison of the directional wave spectra measured with various wave-recording buoys including the cloverleaf buoy is now in progress in NOAA. This paper reports the results of the analysis of typical wave spectra obtained in the ARSLOE area under steady winds. Particularly the study is focused on the similarity form of the wind wave spectra [1]-[3] .

\section{MEASUREMENTS}

\section{Apparatus}

The cloverleaf buoy developed at Kyushu University is almost the same as that of the National Institute of Oceanog- 